\section{Simulations, Games, and Modeling Tools for Learning}

Ton de Jong, Ard Lazonder, Margus Pedaste, and Zacharias Zacharia

\section{Introduction}

Learning in an active way is regarded as a necessary condition for acquiring deep knowledge and skills (e.g., Freeman et al., 2014). Experiential and inquiry learning are specific forms of learning in which students make active choices (choosing the next step in performing an action, changing the value of a variable), experience the consequences of their own actions, and are stimulated to adapt their knowledge and skills in response to these experiences. Experiential and inquiry learning can take place in real environments (a "wet" lab or a practical) but are nowadays increasingly enabled by technologies such as games, simulations, and modeling environments. In this chapter, we first give an overview of these technologies and discuss how they can be used in a diversity of educational settings. We then explain why smart design and careful combination with other instructional approaches and support are necessary. We conclude our chapter by trying to give a glimpse of the future.

\section{Technologies for Experiential and Inquiry Learning}

\section{Simulations}

Simulations have a long history and come in a great variety of forms (de Jong, 2016). Simulations are very often created for science topics such as physics, chemistry, and biology, but they also exist for the behavioral sciences. For example, many psychology courses now offer a set of online simulations that students can explore (e.g., a simulation in which students can practice conditioning with a virtual dog; Hulshof, Eysink, \& de Jong, 2006). Figure 25.1 shows an example of a simulation (or virtual lab) for the physics domain of electricity in which students can create and test their own electrical circuits.

Computer simulations for learning basically consist of two components: an underlying computational model that simulates a process or phenomenon and an interface that enables student to interact with this model (de Jong \& van Joolingen, 2008). Across simulations, the underlying models can cover very different domains and levels of complexity and the interfaces can differ widely in appearance and facilities offered. Interfaces can range from simple and functional to displaying complex and realistic representations, sometimes even including realistic haptic input (Han \& Black, 2011) or 3-D virtual reality (Bonde et al., 2014). Simulations may also offer augmentations for embodied input facilities (Lindgren, Tscholl, Wang, \& Johnson, 2016), or provide features that cannot be seen
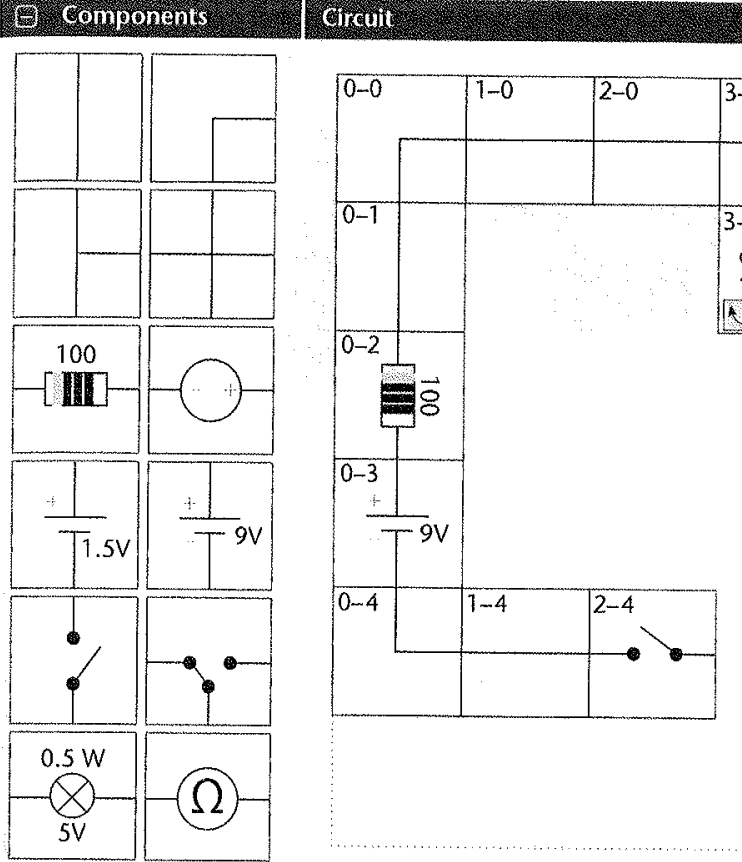

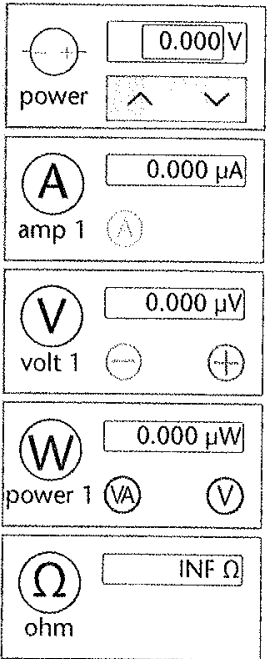

Figure 25.1 Electrical Circuit Laboratory From the Go-Lab Collection (www.golabz.eu)

(Ibáñez, Di Serio, Villarán, \& Delgado Kloos, 2014) or felt in the real world (Bivall, Ainsworth, \& Tibell, 2011). Bivall et al. (2011, p. 700), for example, added a haptic device to a chemistry simulation allowing students to "feel the interactions (repulsive and attractive) between molecules as forces." These authors found that students acquired better conceptual knowledge with the help of the haptic device. Han and Black (2011) found similar results when a joystick providing haptic feedback about forces was added to a simulation with which students could experiment with gears An overview of these types of features is given in Zacharia (2015).

Nowadays, simulations can be found online in many (dedicated) repositories. Some well-known examples are PhET (Wieman, Adams, \& Perkins, 2008), Amrita (Achuthan et al., 2011), and ChemCollective (Yaron, Karabinos, Lange, Greeno, \& Leinhardt, 2010). Some of these repositories offer instructional material around the simulations, while other repositories (e.g., Ing-ITS; Gobert, Baker, \& Wixon, 2015) offer simulations in a sequence of activities including adaptive tools. Still other repositories include authoring facilities to create learning environments around a simulation. Examples of these are WISE (Slotta \& Linn, 2009) and Go-Lab (de Jong, Sotiriou, \& Gillet, 2014).

Lab exercises have always been part of science education (Hofstein \& Lunetta, 2004; Waldrop 2013). These lab exercises traditionally focus on the learning of a skill (e.g., operating a piece of equipment or making a medical diagnosis). What makes the use of technology interesting here (apart from practical issues such as maintenance costs of real labs, etc.) is that many different situations can be offered systematically, so that the skills can be practiced in various circumstances. Figure 25.2 shows an example of a VR (virtual reality) simulation on how to follow the correct protocols in a laboratory (Bonde et al., 2014). Learning a skill from a simulation has received a prominent place in the field of medicine (see, for example, McGaghie, Issenberg, Petrusa, \& Scalese, 2010 for an overview). Extant research reveals that simulations are being used to enhance doctors' clinical skills in controlled and safe practice environments, as well as to support future research, practice, and innovation in medicine (Fincher \& Lewis, 2002). 


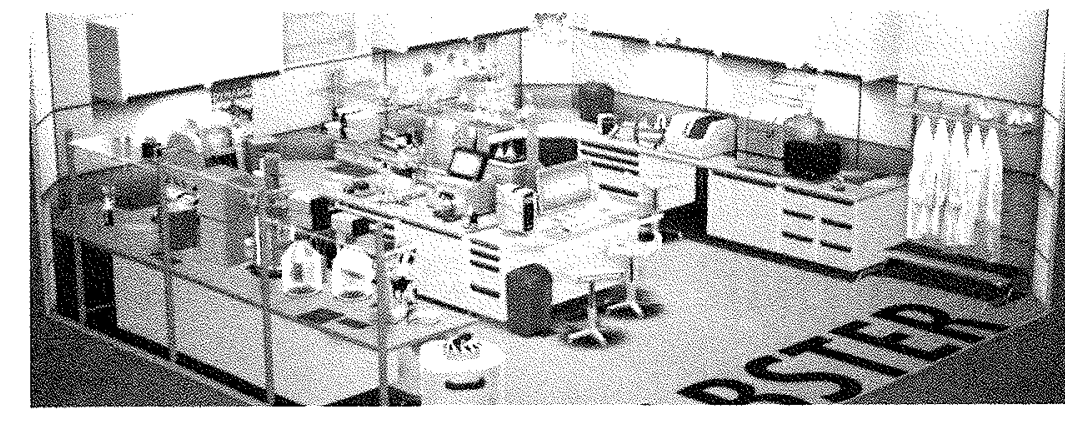

Figure 25.2 Learning Chemistry Laboratory Skills in a VR Simulation (Labster) Source: For Labster, see Bonde et al, (2014).

Other advantages of simulations compared to "wet" labs include that computer technology permits the fast manipulation of many variables and immediate feedback from the simulation, the introduction of situations that are not possible in a school lab, and the use of augmented reality (de Jong, Linn, \& Zacharia, 2013). This also means that there can be a shift in emphasis from learning the more procedural knowledge in a lab (how to perform the experiment) to (also) acquiring deep conceptual knowledge about the underlying domain. This focus on acquiring conceptual knowledge is central to what is called inquiry learning (Rönnebeck, Bernholt, \& Ropohl, 2016; Linn, McElhaney, Gerard, \& Matuk, this volume).

\section{Games}

Some types of games (those with an underlying computational model) are closely related to simulations; these games add features to a simulation such as competition, goal setting, rules and constraints, rewards, role playing and/or surprise (Leemkuil \& de Jong, 2011; see Fields \& Kafai, this volume). Examples of such games are Electric Field Hockey (Miller, Lehman, \& Koedinger, 1999) or Supercharged! (Anderson \& Barnett, 2013). Games can be used like simulations in the sense that students manipulate variables and learn from observing the consequences of their manipulations, but with the added motivational aspects of the game characteristics. As with simulations, one type of games focuses on the acquisition of skills, such as how to do the job of a knowledge engineer in a large company (Leemkuil \& de Jong, 2012) or how to act in emergency situations (van der Spek, van Oostendorp, \& Meyer, 2013).

\section{Modeling Tools}

A third technology useful for active learning is modeling tools. In learning by modeling, students themselves create the models underlying simulations (de Jong \& van Joolingen, 2008). During this process, they develop an understanding of the phenomenon or system being modeled. A modeling process may involve several steps: making systematic observations and collecting data about the phenomenon or system at hand; developing a (computer) model of the phenomenon or system based on those observations and data modeling; evaluating the model according to its degree of resemblance to the actual phenomenon or system, its predictive power and its explanatory adequacy; and revising and applying the model (Louca \& Zacharia, 2015; Windschitl, Thompson, \& Braaten, 2008). These steps keep repeating, not necessarily in this order, through iterative cycles of evaluation and refinement, until the model reaches a state that provides "insights" into the phenomenon or system being represented (National Research Council, 2012, p. 57). For example, Papaevripidou and Zacharia (2015) involved physics and science education graduates in a modeling-based learning activity concerning 1-D elastic collisions of two masses. The participants observed videos on 1-D elastic collisions of two masses colliding (stimulus) and then used a computer modeling environment to construct a model that could potentially represent all possible scenarios where two masses collide elastically in one dimension. The study showed how the students' models progressed after passing through several cycles of evaluation and revision, until they developed a generalized model with optimal predictive power. Computer-based modeling tools use different modeling principles and languages (e.g., system dynamics; Wetzel et al., 2016), which in turn correspond to different interfaces ranging from more textual to graphical or even drawing-based representations (Bollen \& van Joolingen, 2013).

\section{How Can We Make Experiential and Inquiry Learning Effective?}

Just providing students with an open simulation, game, or modeling tool may not be productive. In the next two sections, we discuss two design principles that help to create effective learning experiences.

\section{Sequencing of Experiences}

One specific characteristic of the type of environments discussed in this chapter is that they allow students to decide their own route. However, students may not know where to start so that they may begin with elements of the domain that are, at that point, beyond their reach. So, within the freedom of open learning environments, structuring of the domain is needed, just as in each curriculum. This structuring can be done in a number of ways. First, the domain can be gradually opened up through successively adding more variables (model progression). This means that students do not immediately see the simulation in its full complexity; it is built up gradually (first only velocity present, then acceleration added, etc.; see, e.g., White \& Frederiksen, 1990). In games this is a well-accepted principle. Once having completed a level in a game, the players (learners) move to the next level, which offers greater complexity and challenges. Playing at the right level means that students work at the edge of their current knowledge and skill level. They can play the game at that level without being frustrated, and can anticipate moving to a higher level when the current level is mastered. Lazonder and Kamp (2012) compared a group of (young) students learning with a complete simulation on the reverberation time of a gong, with a group of students who were working through the (four) variables one after each other. They found that the latter group performed more systematic experiments and gained more knowledge. In the case of modeling, Mulder, Lazonder, and de Jong (2011) compared two modes of model progression (by successively introducing more variables or by making the relations between variables gradually more specific) and found that students in both model progression groups created better models than students from a group without model progression. Another way to sequence progress through the domain is to provide students with assignments that stimulate them to explore different parts of the domain or to practice increasingly complex skills. In this case, the underlying model stays the same during the learning activity, but by considering different situations or investigating different variables that are indicated in the assignment, students are guided in covering all aspects of the domain in an appropriate sequence. An example of this is described in Trout, Lee, Moog, and Rickey (2008) who outlined in detail how inquiry learning can be used in chemistry education and listed a dedicated set of assignments to guide students through the inquiry process. In a game on learning about propositional reasoning, ter Vrugte et al. (2015) not only used different levels of difficulty in the game, but also introduced a number of sub-games, each one containing situations and assignments dedicated to a specific sub-skill in the game. 


\section{Instructional Support}

Most research on the effectiveness of instructional support revolves around the design of software tools that either aim to alleviate specific difficulties students encounter during the learning process (Zacharia et al., 2015) or guide students through all stages of the activity (Pedaste et al., 2015). De Jong and Lazonder (2014) classified the types of instructional support embedded within simulationbased learning environments, and their typology applies just as well to games and modeling tools.

The least specific type of support, referred to as process constraints, essentially matches the sequencing principle described in the previous section. Direct presentation of information is the most explicit type of support. It can be delivered through the learning environment before and during the learning process-for instance, in help files or by a pedagogical agent. A typical example can be found in Shakshouka Restaurant, a business simulation game for children to strengthen their financial and math skills (Barzilai \& Blau, 2014). To avoid children developing only an implicit understanding of the central concepts of cost, price, and profit, the game contained an online study unit that children could consult before playing the game. The children who completed this unit scored higher on a math problem posttest than the children who only played the game.

Support at intermediate levels of specificity includes prompts, heuristics, and scaffolds. An example of scaffolding was described by ter Vrugte and colleagues, who embedded faded worked-out examples in a math game about proportional reasoning (ter Vrugte et al., 2017). Vocational education students who played this game received a partly filled-out template of the solution steps and could solve the problem by completing the missing steps. As students progressed through the game's levels, the number of filled-out steps was gradually reduced. This scaffolding proved to be effective: students who had access to worked examples during game play scored significantly higher on a proportional reasoning posttest than students who played the game without them (see Tabak \& Kyza, this volume, for an overview on scaffolding).

Prompts and heuristics are offered during the learning process to remind students of certain actions and the way they could be performed. Prompts and heuristics should be carefully designed in order to minimize disruption of the flow of the activity, which makes them perhaps somewhat less appropriate for use in games. In simulations, however, both types of support have been successfully applied to promote self-explanations, which, in turn, enhance learning outcomes. In one study (Johnson \& Mayer, 2010), a simple question prompt ("Provide an explanation for your answer in the space below") was added to a simulation of an electric circuit, whereas Berthold, Eysink, and Renkl (2009) used a fill-in-the-blanks format to encourage students to self-explain the to-be-learned principles of probability. In both studies, prompted students acquired more topic knowledge than their counterparts who interacted with a simulation without prompts.

Combining open, active, learning environments with direct instruction (concurrent or sequential) may also help students in the learning process. Overall, for both games and simulations, studies report positive effects of this combination, with an overall tendency to favor presentation of the information before the game or simulation compared to after it (Arena \& Schwartz, 2014; Barzilai \& Blau, 2014; Brant, Hooper, \& Sugrue, 1991; Wecker et al., 2013) with some studies reporting superior effects of presenting the information both before and concurrently with the simulation (Lazonder, Hagemans, \& de Jong, 2010).

Meta-analyses show that interventions like those above that combine support with inquiry enhance learning compared to unassisted inquiry (d'Angelo et al., 2014; Lazonder \& Harmsen, 2016) and lead to better knowledge acquisition compared to expository forms of instruction (Alfieri, Brooks, Aldrich, \& Tenenbaum, 2011). Guidance is not typically added to games, from the fear that adding guidance may interfere with the flow of the game, but a recent review study showed that games that were augmented with support outperformed games without that support (Clark, TannerSmith, \& Killingsworth, 2016; see Fields \& Kafai, this volume). Despite the overall conclusion that support works, little is known about the relative effectiveness of different types of support. Recently, however, Lazonder and Harmsen (2016) concluded from their meta-analysis that students create better products (e.g., models, concept maps, lab reports) during an inquiry if they receive more specific support. Although the specificity of the support did not show an effect on learning outcomes, it did impact learning activities, such that young, less experienced learners tended to benefit more from specific support than older, more experienced learners.

\section{Learning Sciences and Research Methods}

The urge to include technology-based simulations and modeling tools in education is based on a number of theoretical prenises. The first is that following a scientific inquiry cycle possibly includes encountering a cognitive conflict between existing ideas and data that come from experiments (Limón, 2001). Based on such conflicts, students would then be stimulated to adapt their existing knowledge. This theoretical notion is closely related to the cognitive theories of schema development and adaptation (see e.g., Chi, Glaser, \& Farr, 1988). A second theoretical notion underlying the impetus for simulation-based learning is that simulations often use multiple representations. These different representations (graphs, animations, equations, tables, etc.) are dynamic and must be connected by students, which leads to processes of knowledge abstraction (Ainsworth, 2006; Ainsworth, this volume), as also explained by Mayer's multimedia theory (Mayer, 2009). A third underlying principle is that in simulation-based learning students are in charge of their own learning process, which, according to theories of social learning, leads to higher motivation and especially to intrinsic motivation (Ryan \& Deci, 2000), while the students get control over the learning process by planning, monitoring, and reflecting about it. In this way, simulation and modeling also support selfregulated learning (Zimmerman, 1990). A fourth relevant theoretical approach is constructionism (e.g., Kafai \& Resnick, 1996). According to this theory, students learn through the process of identifying and representing the components that comprise a phenomenon. These components include objects (e.g., particles), processes (e.g., free fall), entities (e.g., acceleration), and interactions (e.g., how entities interact with objects or processes). In other words, the learner strips down the phenomenon into its components (an analysis process) and then builds up the phenomenon in a modeling environment (a synthesis process). However, the underlying premises behind each of these approaches could be overly optimistic; for example, sometimes students do not adapt their knowledge in response to anomalous data (Chinn \& Brewer, 1993) or they fail to connect representations (van der Meij \& de Jong, 2006). In these cases, instructional support is needed for successful learning.

The research methods used in this field can be divided into: design-based research that basically focuses on the design of a specific simulation or modeling tool through iterative rounds of improvement (Wang \& Hannafin, 2005; see Puntambekar, this volume, for an introduction to design-based research); experimental studies in which different variants of a learning environment are compared or in which a modeling- or simulation-based learning environment is compared to another type of instruction (for an overview of these type of studies, see d'Angelo et al., 2014); and studies that focus on the learning process and have a qualitative character, using, for example, thinking aloud techniques (Furberg, Kluge, \& Ludvigsen, 2013) or using student interaction data to collect information on the learning process or to predict students' developing knowledge (e.g., Käser, Hallinen, \& Schwartz, 2017).

\section{Future Developments}

Most of the cited studies used a "one-size-fits-all" approach, in that one particular type of instructional support was available to all students throughout the entire learning process. Evidence is now accumulating that a more sophisticated approach is needed that takes the interplay between student characteristics and the provided guidance into account; specific scaffolds may be more or less 
effective depending on the student's prior knowledge. Future efforts to investigate and employ these technologies should therefore be more sensitive to individual differences and at the same time address ways to embed them in the curriculum.

Authoring facilities offered by repositories such as WISE and Go-Lab enable teachers to adapt instructional support to student characteristics up-front. Teachers can configure a learning environment such that 10 th graders receive more background information than 12 th graders, or the less knowledgeable students in the class receive a partially specified model whereas the more knowledgeable ones must build this model from scratch (cf. Mulder, Bollen, de Jong, \& Lazonder, 2016). Possibilities like these are likely to grow in the near future, and research must provide teachers with specific guidelines on which levels of support are appropriate for which groups of learners.

Going beyond differentiation based on learner characteristics, support should also adapt to what students create or do during the learning process. Teachers can offer this support on the spot while watching their students, but developments in learning analytics (see Rosé, this volume, for an overview on learning analytics and educational data mining) have greatly advanced the possibilities for teachers and software agents to work in synergy. For example, the Inq-ITS platform offers physics simulations that monitor middle school students' actions and provides automatic support right when it is needed, thus enabling the teacher to resolve more specific issues through personal coaching and feedback (Gobert, Sao Pedro, Raziuddin, \& Baker, 2013). Likewise, Ryoo and Linn (2016) developed an automated scoring system that assessed the qualities of student-created concept maps and generated guidance based on assessment outcomes. Research and development of such automated support facilities can play a major role in the future development of effective experiential and inquiry-based learning methods.

\section{Conclusion}

Modem, web-based technology enables the use of simulations and modeling environments worldwide and increases the accessibility of online labs, simulations, and modeling tools. This increases their usage and with appropriate instructional embedding, simulations, games, and modeling tools become very effective technologies for learning. These technologies and the associated types of learning fit into a trend that pedagogical approaches in schools are gaining versatility and flexibility and are offered to students in all types of combinations. Learning with these technologies can be very nicely integrated with collaborative learning, learning in real (wet) labs and in flip-the-classroom set-ups in which data from interactions or products from the virtual experiences can be the input for class discussions. Issues for attention are the technology skills that teachers need and new pedagogies that should go along with these new developments.

\section{Acknowledgment}

This work was partly prepared in the context of the Next-Lab project, which has received funding from the European Union's Horizon 2020 Research and Innovation Programme under Grant Agreement No. 731685. This publication reflects the authors' views only, and the European Commission is not responsible for any use that may be made of the information it contains.

\section{Further Readings}

Clark, D. B., Tanner-Smith, E. E., \& Killingsworth, S. S. (2016). Digital games, design, and learning: A systenatic review and meta-analysis. Review of Educational Research, 86, 79-122.

This meta-analysis synthesized the results of 57 primary studies on learning with digital games, including simulation games. Main findings indicate that digital games significantly enhanced student learning relative to non-game control conditions. The meta-analysis also compared augmented game designs to standard game designs. Across 20 studies, the learning effect of the augmented designs was higher than that of standard designs. Together these findings indicate that digital games can be beneficial for learning, and that their educational

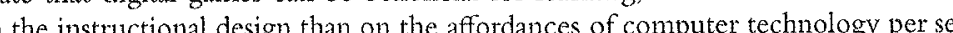

d'Angelo, C., Rutstein, D., Harris, C., Bernard, R., Borokhorski, E., \& Haertel, G. (2014), Simulations for STEM learaing: Systematic review and meta-analysis. Menlo Park, CA: SRI Intemational.

This meta-analysis had two main research questions: Do students learn more from computer simulations than from other forms of instruction; and do students learn more from plain simulations or from simulations that are combined with other instructional measures? Including 42 studies, the first meta-analysis showed, in a consistent pattern, a clear advantage for simulation-based instruction over non-simulation instruction. Based on 40 comparisons, the second meta-analysis showed that enhanced simulations are more effective than non-enhanced ones, with

McGaghie, W. C., Issenberg, S. B., Petrusa, E. R., \& Scalese, R. J. (2010). A critical review of simulation-based medical education research: 2003-2009. Medical Education, 44, 50-63.

This literature review addresses the research on simulation-based medical education (SBME) up until 2009. Its authors identify and reflect upon the features and best practices of SBME that medical educators should take into account for optimizing learning through the use of simulations. Each of these features is discussed according to the empirical evidence available in the domain of SBME. The authors conclude that research and development on SBME has improved substantially and that SBME has a lot to offer for the training of future doctors.

Windschitl, M., Thompson, J., \& Braaten, M. (2008). Beyond the scientific method: Model-based inquiry as a new paradigm of preference for school science investigations. Science Education, 92, 941-967.

The authors discuss findings from a series of five studies and offer an alternative vision for investigative sciencemodel-based inquiry. The aim of model-based inquiry is to engage learners more deeply in the learning process. They focus on the learners' ideas and show that, by modeling, these ideas should be testable, revisable, explanatory, conjectural, and generative. These ideas are also applicable when using simulations that are controllable by the sudents and where the learning process could be supported by the teacher or specifically designed worksheets.

Zacharia, Z. C. (2015). Examining whether touch sensory feedback is necessary for science learning through experimentation: A literature review of two different lines of research across K-16. Eductitional Research Review, 16, 116-137.

This review aimed at examining whether touch sensory feedback offered through physical or virtual (with haptic feedback) manipulatives affects students' science learning differently, compared to virtual manipulatives that do not offer touch sensory input (no use of haptic devices). The evidence came from two different lines of reseach, mamely, from studies focusing on comparing physical and virtual manipulatives (with no haptic feed reach, the from feedback through haptic devices. The meta-analysis of these studies revealed that touch sensory feedback is not always a prerequisite for learning science through experimentation.

\section{NAPLeS References}

Jacobson, M., 15 minutes on complex systems [Video file]. In NAPLeS video series. Retrieved October 19, 2017, from http//isls-naples.psy.linu.de/video-resources/guided-tour/15-minutes-jacobson/index.html

Limn, M., 15 minutes on inquiry leaming [Video file]. In NAPLeS video series. Retrieved October 19, 2017, from http://isls-naples. psy.lmu.de/video-resources/guided-tour/15-minutes-linn/index.html

\section{References}

Achuthan, K., Sreelatha, S. K. Surendran, S. K., Diwakar, S., Nedungadi, P., Humphreys, S., et al. (2011, October-November).The VALUE@Amrita virtual labs project: Using web rechmology to provide virtual laboratory access to students. Paper presented at the 2011 IEEE Global Humanitarian Technology Conference (GHTC)

Ainsworth, S. (2006). Deft: A conceptual framework for considering learning with multiple representations. Learning and Instruction, 16, 183-198.

Ainsworth, S. (2018). Multiple representations and multimedia learning. In F. Fischer, C. E. Hmelo-Silver, S. R. Goldman, \& P. Reimann (Eds.), Intermational handbook of the leaming sciences (pp. 96-105). New York: Routledge. Alfieri, L., Brooks, P. J., Aldrich, N. J., \& Tenerbaum, H. R. (2011). Does discovery-based instruction enhance learning? Journal of Educational Psychology, 103, 1-18. 
Anderson, J. L., \& Barnett, M. (2013). Learning physics with digital game simulations in middle school science. Joumal of Science Education and Technology, 22, 914-926.

Arena, D. A., \& Schwartz, D. L. (2014). Experience and explanation: Using videogames to prepare students for formal instruction in statistics. Joumal of Science Education and Techology, 23, 538-548.

Barzilai, S., \& Blau, I. (2014). Scaffolding game-based learning: Impact on learning achievements, perceived learning, and game experiences. Computers $\&$ Education, 70, 65-79.

Berthold, K., Eysink, T. H. S., \& Renkl, A. (2009). Assisting self-explanation prompts are more effective than open prompts when learning with multiple representations. Instructional Science, 37, 345-363.

Bivall, P., Ainsworth, S., \& Tibell, L. A. E. (2011). Do haptic representations help complex molecular learning? Science Education, 95, 700-719.

Bollen, L., \& van Joolingen, W. R. (2013). SimSketch: Multiagent simulations based on learner-created sketche for early science education. IEEE Transactions on Leaning Technologies, 6, 208-216.

Bonde, M. T., Makransky, G., Wandall, J., Larsen, M. V., Morsing, M., Jarmer, H., \& Sommer, M. O. A. (2014) Improving biotech education through gamified laboratory simulations. Nature Biofechnology, 32, 694-697.

Brant, G., Hooper, E., \& Sugrue, B. (1991). Which comes first, the simulation or the lecture? Jourtul of Educational Computing Research, 7, 469-481.

Chi, M. T. H., Glaser, R., \& Farr, M. (Eds.). (1988). The muture of expertise. Hillsdale, NJ: Lawrence Erlbaum.

Chinn, C. A., \& Brewer, W. F. (1993). The role of anomalous data in knowledge acquisition: A theoretica framework and implications for science instruction, Review of Educational Research, 63, 1-51.

Clark, D. B., Tanner-Smith, E. E., \& Killingsworth, S. S. (2016). Digital games, design, and learning: A systematic review and meta-analysis. Reriew of Educational Reseurch, 86, 79-122.

d'Angelo, C., Rutstein, D., Harris, C., Bernard, R., Borokhovski, E., \& Haertel, G. (2014). Simulations for STEM learning: Systematic review and meta-analysis. Menlo Park, CA: SRI International.

de Jong, T. (2016). Instruction based on computer simulations and virtual labs. In R. E. Mayer \& P. A. Alexander (Eds.), Handbook of research on learming and instruction (2nd ed., pp. 1123-1167). New York: Routledge.

de Jong, T., \& Lazonder, A. W. (2014). The guided discovery principle in multimedia learning. In R. E. Mayer (Ed.), The Cambridge hatudbook of multimedia leaming (2nd ed., pp. 371-390). Cambridge, UK: Cambridge University Press.

de Jong, T., Linn, M. C., \& Zacharia, Z. C. (2013). Physical and virtual laboratories in science and engineering education. Science, 340, 305-308,

de Jong, T., Sotirion, S., \& Gillet, D. (2014). Innovations in STEM education: The Go-Lab federation of online labs. Sinat Learning Enviromments, 1, 1-16.

de Jong, T., \& van Joolingen, W. R. (2008). Model-facilitated leaming. In J. M. Spector, M. D. Merill, J. v. Merriënboer, \& M. P. Driscoll (Eds.), Handbook of research on educational communtication and technology (3rd ed., pp. 457-468). New York: Lawrence Erlbaum.

Fields, D. A., \& Kafai, Y. B. (2018). Games in the learning sciences: Reviewing evidence from playing and making games for learning. In F. Fischer, C. E. Hmelo-Silver, S. R. Goldman, \& P. Reimann (Eds.), Internationd handbook of the learning sciences (pp. 276-284). New York: Routledge.

Fincher, R. M. E., \& Lewis, L. A. (2002). Simulations used to teach clinical skills, In G. R. Norman, C. P. M van der Vleuten, \&. D. J Newble (Eds) International handbook of reseurch in medical education (pp. 499-535). Dordrecht, Netherlands: Kluwer Academic.

Freeman, S. Eddy, S. L., McDonough, M. Snith, M. K., Okoroafor, N., Jordt, H. \& Wenderoth, M. P. (2014). Active learning increases student performance in science, engineering, and mathematics. Procedditgs. of the National Academy of Sciences, 111, 8410-8415.

Furberg, A., Kluge, A., \& Ludvigsen, S. (2013). Student sensemaking with science diagrams in a computerbased setting. Intermational Journal of Computer-Supported Collaborative Learming, 8, 41-64.

Gobert, J. D., Baker, R. S., \& Wixon, M. B. (2015). Operationalizing and detecting disengagement within online science microworlds. Educational Psychologist, 50, 43-57.

Gobert, J. D., Sao Pedro, M. A., Raziuddin, J., \& Baker, R. S. (2013). From log files to assessment metrics: Measuring students' science inquiry skills using educational data mining. Joumal of the Learming Sciences, 22, 521-563.

Han, I., \& Black, J. B. (2011). Incorporating haptic feedback in a simulation for learning physics. Computers 8 Education, 57, 2281-2290.

Hofstein, A., \& Lunetta, V. N. (2004). The laboratory in science education: Foundations for the twenty-first century. Science Education, 88, 28-54.

Hulshof, C. D., Eysink, T. H. S., \& de Jong, T. (2006). The ZAP project: Designing interactive computer tools for learning psychology. Innovations in Education \& Teadhing International, 43, 337-351.

Ibáñez, M. B., Di Serio, A., Villarán, D., \& Delgado Kloos, C. (2014). Experimenting with electromagnetism using augmented reality: Impact on flow student experience and educational effectiveness. Computers 6 Education, $71,1-13$
Johnson, C. I., \& Mayer, R. E. (2010). Applying the self-explanation principle to multimedia learning in a computer-based game-like environment. Computers in Human Bchavior, 26, 1246-1252.

Kafai, Y. B., \& Resnick, M. (Eds.). (1996). Constructionism in practice: Designing, thinking, and leaning in a digital world. Mahwah, NJ: Lawrence Erlbaum.

Käser, T., Hallinen, N. R., \& Schwartz, D. L. (2017). Modeling exploration strategies to predict student performance within a learning entrironment and beyond. Paper presented at the Proceedings of the Seventh Internationa Learning Analytics \& Knowledge Conference.

Lazonder, A. W., Hagemans, M. G., \& de Jong, T. (2010). Offering and discovering domain information in sinnulation-based inquiry learning. Learning and Instruction, 20, 511-520

Lazonder, A. W., \& Harmsen, R. (2016). Meta-analysis of inquiry-based learning: Effects of guidance. Revicm of Educational Research, 86, 681-718.

Lazonder, A. W., \& Kamp, E. (2012). Bit by bit or all at once? Splitting up the inquiry task to promote children's scientific reasoning. Leaning and Instruction, 22, 458-464.

Leemkuil, H., \& de Jong, T. (2011). Instructional support in games. In S. Tobias \& D. Fletcher (Eds.), Can computer ganves be used for instruction? (pp. 353-369). Charlotte, NC: Information Age Publishers.

Leemkuil, H., \& de Jong, T. (2012). Adaptive advice in learning with a computer-based strategy game. Academ of Management Leaminty \& Education, 11, 653-665.

Limón, M. (2001). On the cognitive conflict as an instructional strategy for conceptual change: A critical appraisal, Leatming and Instruction, 11, 357-380.

Lindgren, R., Tscholl, M., Wang, S., \& Johnson, E. (2016). Enhancing learning and engagement through embodied interaction within a mixed reality simulation. Computers \& Education, 95, 174-187.

Linn, M. C., McElhaney, K. W., Gerard, L., \& Matuk, C. (2018). Inquiry learning and opportunities for technology. In F. Fischer, C. E. Hmelo-Silver, S. R. Goldman, \& P. Reimamn (Eds.), Intemational handbook of the learning sciences (pp. 221-233). New York: Routledge.

Louca, L. T., \& Zacharia, Z. C. (2015). Examining learning through modeling in K-6 science education. Joum of Science Education and Technology, 24, 192-215.

Mayer, R. E. (2009). Multimedia leaning (2nd ed.). New York: Cambridge University Press.

McGaghie, W. C., Issenberg, S. B., Petrusa, E. R., \& Scalese, R. J. (2010). A critical review of simulation-based medical education research: 2003-2009. Medical Education, 44, 50-63.

Miller, C. S., Lehman, J. F., \& Koedinger, K. R. (1999). Goals and learning in microworlds. Cognitive Science, $23,305-336$

Mulder, Y. G., Bollen, L., de Jong, T., \& Lazonder, A. W. (2016). Scaffolding learning by modelling: The effects of partially worked-out models. Joumal of Research in Science Teaching, 53, 502-523.

Mulder, Y. G., Lazonder, A. W., \& de Jong, T. (2011). Comparing two types of model progression in an inquiry learning enviromment with modelling facilities. Learning and Instruction, 21, 614-624.

National Research Council. (2012). A framework for $\mathrm{K}-12$ science education: Practices, crosscutting concepts, and core ideas. Washington, DC: National Academies Press.

Papaevripidou, M., \& Zacharia, Z. C. (2015). Examining how students' knowledge of the subject domain affects their process of modeling in a computer programming environment. Joumal of Computers in Edtuation, 2, 251-282 Pedaste, M Mäeots. M. Siiman, L A de Jong T, van Riesen, S. A N. Kamp, E. T. et al. (2015). Phases of inquiry-based learning. Definitions and inquiry cycle. Educational Research Repiew, 14,47-61.

inquiry-based learning: Definitions and inquiry cycle. Educational Research Retrew, 14, 47-61. P. Reimann (Eds.), International handbook of the learning sciences (pp. 383-392). New York: Routledge.

Rönnebeck, S., Bernholt, S., \& Ropohl, M. (2016). Searching for a common ground-A literature review of empirical research on scientific inquiry activities. Studies in Science Eduction, 1-37. doi:10.1080/03057267.2016.1206351 R.osé, C. P. (2018). Learning analytics in the Learning Sciences. In F. Fischer, C. E. Hmelo-Silver, S. R. Goldman, \& P. Reimamn (Eds.), International handbook of the learning sciences (pp. 511-519). New York: S. R. Gold

Routledge.
Ryan, R. M., \& Deci, E. L. (2000). Self-determination theory and the facilitation of intrinsic motivation, social yan, R. M., \& Deci, E. L. (2000). Self-determination theory and
development, and well-being. American Psychologist, 55, 68-78.

Ryoo, K., \& Linn, M. C. (2016). Designing automated guidance for concept diagrams in inquiry instruction. Joumal of Research in Science Teaching, 53, 1003-1035.

Slotta, J. D., \& Linn, M. C. (2009). WISE science: Web-based inquiry in the dussroom. New York: Teachers College Press. Tabak, I., \& Kyza., E. (2018). Research on scaffolding in the Learning Sciences: A methodological perspective. In F. Fischer, C. E. Hmelo-Silver, S. R. Goldman, \& P. Reimann (Eds.), International handbook of the learming sciences (pp. 191-200). New York: Routledge.

ter Vrugte, J., de Jong, T., Wouters, P., Vandercruysse, S., Elen, J., \& van Oostendorp, H. (2015). When a game supports prevocational math education but integrated reflection does not. Joumal of Computer Assisted Leaming, 31, 462-480. 
ter Vrugte, J., de Jong, T., Wouters, P., Vandercruysse, S., Elen, J., \& van Oostendorp, H. (2017). Computer game-based mathematics education: Embedded faded worked examples faclitate knowledge acquisition. Learning and Instruction, 50, 44-53.

Trout, L., Lee, C. L., Moog, R., \& Rickey, D. (2008). Inquiry learning: What is it? How do you do it? In S. L. Bretz (Ed.), Chemistry in the national science education standards: Models for meaningful leaming in the high school chetristry diasstrom (2nd ed., pp. 29-43): Washington, DC: American Chemical Society.

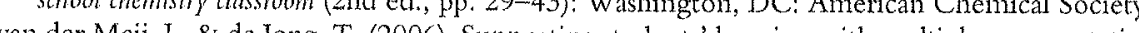

sim Meij, ., \& de Jong, T. (2006). Supporting students' learning with multiple representations in a dynamic simulation-based leaning envionment. Lenning and lnsmution, 16, 192-212.

van der Spek, E. D., van Oostendorp, H., \& Meyer, J. J. C. (2013). Introducing surprising events can stimulate deep learning in a serious game. British Journal of Educational Techrology, 44, 156-169.

Waldrop, M. M. (2013). The virtual lab. Nature, 499, 268-270.

Wang, F., \& Hannafin, M. J. (2005). Design-based research and technology-enhanced learning environments Educationd Technology Research and Development, 53, 5-23.

Wecker, C., Rachel, A., Heran-Dörr, E., Waltner, C., Wiesner, H., \& Fischer, F. (2013). Presenting theoretical ideas prior to inquiry activities fosters theory-level knowledge. Joumal of Research in Science Teaching, 50, $1180-1206$

Wetzel, J., VanLehn, K., Butler, D., Chaudhari, P., Desai, A., Feng, J., et al. (2016). The design and development of the dragoon intelligent tutoring system for model construction: Lessons learned. Interactive Learting Enitronments, 1-21. doi: 10.1080/10494820.2015.1131167

White, B. Y., \& Frederiksen, J. R. (1990). Causal model progressions as a foundation for intelligent learning environments. Artificial Intelligence, 42, 99-157.

Wieman, C. E., Adams, W. K., \& Perkins, K. K. (2008). PhET: Simulations that enhance learning. Science, $322,682-683$.

Windschitl, M., Thompson, J., \& Braten, M. (2008). Beyond the scientific method: Model-based inquiry as a new paradigm of preference for school science investigations. Science Education, 92, 941-967.

Yaron, D., Karabinos, M., Lange, D., Greeno, J. G., \& Leinhardt, G. (2010). The chemcollective-Virtual labs for introductory chemistry courses. Science, 328, 584-585.

Zacharia, Z. C. (2015). Examining whether touch sensory feedback is necessary for science learning through experimentation: A literature review of two different lines of research across $\mathrm{K}-16$. Educational Research Review, 16, 116-137

Zacharia, Z. C., Manoli, C., Xenofontos, N., de Jong, T., Pedaste, M., van Riesen, S. A. N., et al. (2015). Identifying potential types of guidance for supporting student inquiry in using virtual and remote labs: A literature review. Educational Technology Research \& Development, 63, 257-302.

Zimmerman, B. J. (1990). Self-regulated learning and academic achievement: An overview. Educational Psychologist, 25, 3-17.

\section{Supporting Teacher Learning Through Design, Technology, and Open Educational Resources}

Mimi Recker and Tamara Sumner

\section{Introduction}

Several strands of Learning Sciences research have conceptualized teaching as a design activity and examined resulting instructional implications. Participating in design processes can help teachers learn new content and skills (Davis \& Krajcik, 2005), while also serving to support and sustain curricular innovations (Fishman \& Krajcik, 2003). In a seminal review, Remillard (2005) argues that curriculum materials can be viewed as models that teachers engage with in order to design activities for their students. Studies show that teachers who engage closely with curriculum and other highquality materials to design instructional activities can significantly enhance their students' learning (NRC, 2007; Penuel, Gallagher, \& Moorthy, 2011).

Engaging teachers in design has been explored from several perspectives within the Learning Sciences (see Kali, McKenney, \& Sagy, 2015). For example, one strand has examined the kinds of knowledge teachers need to engage in design, while another investigated different trajectories for engaging teachers in design (for example, collaborative design). A third perspective studies technological supports for design processes (Davis \& Krajcik, 2005; Kali, Kenney, \& Sagy, 2015; Matuk, Linn, \& Eylon, 2015; Voogt, Almekindes, van den Akker, \& Moonen, 2005).

New technological arrangements and their affordances to support or enhance learning have been broadly termed cyberlearning. Here, the role of open educational resources (OERs) have been specifically called out as an important component (Borgman et al., 2008). OERs are teaching and learning resources that reside in the public domain or have been released under licensing schemes that allow their free use or customization by others (Atkins, Brown, \& Hammond, 2007; Borgman et al., 2008). They encompass multiple media and resource types, such as animations, videos, scientific data, maps, images, games, simulations, and complete textbooks. OERs can be created by scientific institutions such as NASA, by publishing companies, by university faculty, by $\mathrm{K}-12$ teachers, or by learners of all ages. OERs can be found on the world wide web and in dedicated repositories such as the National Science Digital Library, OERs Commons, or YouTube's education channel, which contains tens of thousands of educational resources.

In this chapter, we focus on the role technology can play in supporting teachers as they engage in design processes using OERs. As teachers work with OERs, teachers engage in a rich set of instructional and design practices: they adapt and combine resources to create new learning materials, share their labor with others by posting new or remixed resources, and contribute metadata about OERs such as ratings, tags, comments, and reviews. Teachers' prior experiences, their perceptions 